\title{
Noise properties of semiconductor waveguides with alternating sections of saturable gain and absorption
}

\author{
Öhman, Filip; Bischoff, Svend; Tromborg, Bjarne; Mørk, Jesper
}

Link to article, DOI:

10.1109/CLEOE.2003.1312253

Publication date:

2003

Document Version

Publisher's PDF, also known as Version of record

Link back to DTU Orbit

Citation (APA):

Öhman, F., Bischoff, S., Tromborg, B., \& Mørk, J. (2003). Noise properties of semiconductor waveguides with alternating sections of saturable gain and absorption. Poster session presented at European Conference on Lasers and Electro-Optics 2003, Munich, Germany. https://doi.org/10.1109/CLEOE.2003.1312253

\section{General rights}

Copyright and moral rights for the publications made accessible in the public portal are retained by the authors and/or other copyright owners and it is a condition of accessing publications that users recognise and abide by the legal requirements associated with these rights.

- Users may download and print one copy of any publication from the public portal for the purpose of private study or research.

- You may not further distribute the material or use it for any profit-making activity or commercial gain

- You may freely distribute the URL identifying the publication in the public portal 


\section{Noise properties of semiconductor waveguides with alternating sections of saturable gain and absorption \\ Filip Öhman, Svend Bischoff, Bjarne Tromborg and Jesper Mork COM, Technical University of Denmark, Build. 345v, DK-2800 Kgs. Lyngby, Denmark, (fo@com.dtu.dk)}

\begin{abstract}
We investigate the dynamical noise properties of saturable semiconductor devices for optical signal processing. A trade-off between noise redistribution and extinction ratio improvement has to be made for alloptical regeneration.
\end{abstract}

\section{Introduction}

Semiconductor optical amplifiers (SOA) have many applications in the field of optical communication systems. In combination with a saturable absorber (SA), regeneration may be achieved. One promising implementation is a sectioned semiconductor waveguide with alternating forward and reverse bias. By concatenating several sections of saturable gain and absorption a significant reshaping of the signal can be obtained, but the noise properties may be compromised.

\section{Noise properties}

The noise of the output signal, which includes amplified noise of the input signal and amplified spontaneous emission (ASE) from the SOA is determined by the small-signal method of [1] and by large-signal simulation. Figure 1 shows the relative intensity noise (RIN) spectra of the output signals. By taking the reciprocal of the integral of the RIN over a chosen bandwidth, the signal-to-noise ratio (SNR) can be calculated.

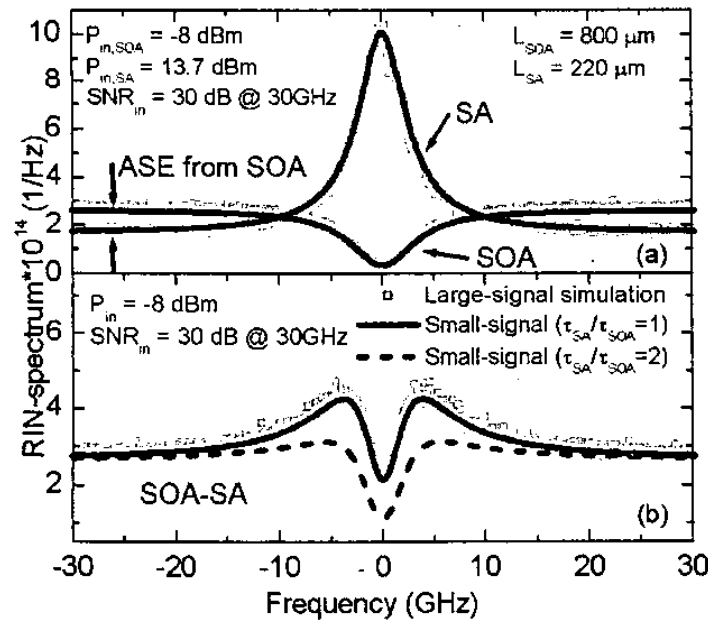

Figure 1 RIN spectra at mark level of a single SOA and a single SA (a) and an SOA followed by the SA (b).

The gain saturation in the SOA leads to substantial noise suppression for low frequencies, which has also been shown experimentally [2]. The reason is that intensity fluctuations are counteracted by the induced changes of the gain. The absorption bleaching in the SA, due to band filling and screening, works in the opposite direction and thus leads to an increase in the noise at low frequencies. This self-modulation in the SOA and SA depends on the amount of saturation and is only operative within a bandwidth determined by the effective carrier lifetime $(\tau)$. When the SOA and SA are combined the resulting $\mathrm{RIN}$-spectrum shows noise suppression for low frequencies but noise enhancement at intermediate frequencies, as seen in Figure 1 (b).

In order to achieve noise suppression over a large bandwidth at the mark level, the speed of the SOA should be high compared to the SA and the operating power should be chosen such that both sections saturate substantially. A slow SA saturates at lower powers and therefore also gives higher total gain for the device. In 2R-regeneration, where the SA is used for suppressing the noise at the space-level, these considerations are especially important since the SA has to saturate before the SOA. The extinction ratio (ER) improvement achieved from the SA, see Figure 2, depends on the input ER. This has to be considered together with the noise redistribution at the mark and space levels.

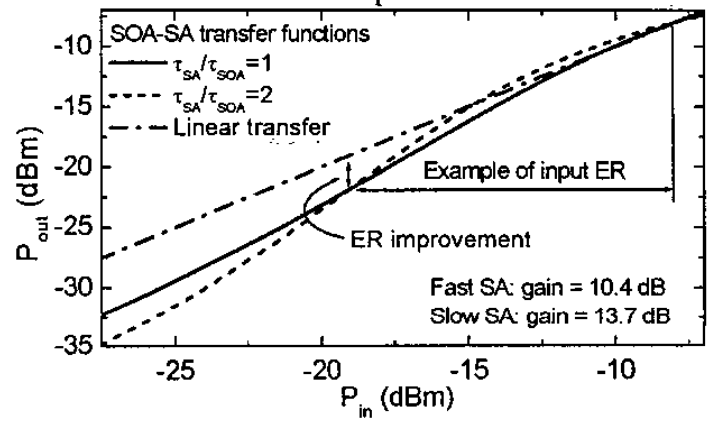

Figure 2 Transfer functions for the device, shifted to give equal output and input power at the chosen mark-level.

For a complete description of the noise properties, the probability density functions (pdf) also need to be known. In the presentation we will show how pdfs can be estimated by large signal simulations, static transfer functions as well as the use of an approximate FokkerPlanck equation.

\section{Conclusions}

We have analysed the trade-off between extinction ratio improvement and noise redistribution in a $2 \mathrm{R}$-regenerator based on a combination of saturable gain and absorption sections. The dynamical noise contributions of the gain and absorber sections partly counteract each other and need to be considered in detail.

\section{References}

[1] M. Shtaif et al., IEEE J. Quantum Electron., 34, 5, pp.869-878, (1998).

[2] K. Sato et al., IEEE J. Select. Topics. Quantum Electron., 7, 2, pp. 328-333, (2001). 